\title{
Post-Laminectomy Spondylolisthesis - A Review of the Posterior Elements and their Contribution to the Stability of the Lumbar Spine
}

\author{
Hwee Weng Dennis Hey ${ }^{*}, 1$, Puang Hur Bernard Lau ${ }^{1}$, Choon Chiet Andrew Hong ${ }^{1}$ and \\ Hwan Tak Hee ${ }^{2}$ \\ ${ }^{1}$ Department of Orthopaedic Surgery, National University Hospital, Singapore \\ ${ }^{2}$ Centre for Spine and Scoliosis Surgery, Paragon Medical Centre, Mount Elizabeth Medical Centre, Singapore
}

\begin{abstract}
As surgical practice changes with increasing new evidence, a review of past experiences often gives us a good idea why we do things the way it is now. Our modern understanding of factors contributing to the stability of the lumbar spine can be represented using posterior decompression of the lumbar spine as an example. Since the late 1900s, the "Christmas tree laminectomy" procedure gained widespread popularity in treating neurogenic claudication and lumbar stenosis. However, this clinical improvement is often transient and patients return with symptom recurrence and findings of spinal instability. Further biomechanical studies and clinical trials looked at modifications to this procedure such as facet sparing laminectomy and laminotomy with improved results. It was then that bony, discoligamentous and muscular factors are increasingly recognized as contributors to the overall stability of the lumbar spine. Surgical decompression of spinal stenosis has to balance between adequate removal of bone and soft tissue for an effective decompression of neural structures, and sufficient retention of bone and soft tissue structures to maintain mechanical stability of the spine. When these stabilizers are compromised, a prophylactic fusion of the spinal unit may be required. Ultimately, the decision to perform laminectomy or laminotomy has to be a clinical judgement based on a combination of surgeon, patient and disease factors.
\end{abstract}

Keywords: Facet joint, instability, lumbar spine, post-laminectomy, spondylolisthesis, laminotomy.

\section{INTRODUCTION}

Stability of the lumbar spine is attributable to several structures in the functional spinal unit. These structures are either bony, discoligamentous or muscular in nature $[1,2]$. Loss of stability can be secondary to physiological ageing or diseases that alter the integrity of the stabilizing structures. Iatrogenic instability can also result after surgery due to the damage or removal of these structures. Depending on which structures are disturbed, the spine may gain hypermobility and lose stability in different planes of movement - sagittal, coronal, and axial.

Previous studies have examined the role of the disc as an anterior stabilizer of the functional spinal unit. Although many experts confirmed that degenerate discs lead to abnormal movement, the cause of lower back pain and its pathophysiology remained poorly defined [3]. In fact, the hypothesis that disc degeneration precedes facet joint degeneration is generally accepted [4-6]. There are reports which believe that this is often dictated by the speed and degree of degeneration [7].

\section{RADICAL LAMINECTOMY AND FACET SPARING LAMINECTOMY}

In the late 1900s, the "Christmas tree laminectomy" procedure for the treatment of spinal stenosis gained widespread

*Address correspondence to this author at the Department of Orthopaedic Surgery, National University Hospital, Singapore; Tel: (+65) 6772 4342; E-mail: hwee_weng_hey@nuhs.edu.sg popularity. This method of decompression was efficacious in treating neurogenic claudication and radiologically confirmed lumbar stenosis. Although the lateral extent of bone removal varies among surgeons, in order to achieve adequate decompression, the surgery was often done with radical laminectomies, accompanied by bilateral facetectomies and foraminotomies. As the procedure involves resection of the posterior elements of the spine in a way resembling a "Christmas tree", hence its name. However, it became evident a few years later that even though this procedure gave patients temporary symptom relief, it also led to a sudden increase in the number of patients developing recurrent neurological symptoms, symptoms of instability, and eventually spondylolisthesis of the lumbar spine [8-10].

Soon it became more recognized that surgical decompression of spinal stenosis is a balance between adequate removal of bone and soft tissue for an effective decompression of neural structures, and retention of sufficient bone and soft tissue structures to maintain mechanical stability of the spine. It was then the role of the facet joints as a stabilizer of the lumbar spine gained interest.

A review of operative cases performed in our institution between 2005 to 2010 using diagnosis and surgical codes showed a series of 20 patients who presented initially with spinal stenosis and developed post-laminectomy spondylolisthesis. They later underwent transformaminal lumbar interbody fusion. Table 1 shows the baseline characteristics of these patients. The mean age was 66.5 years (range 52 to 82 years) and the male:female ratio was 1:4. 
Table 1. Patient Characteristics

\begin{tabular}{|c|c|}
\hline \multicolumn{2}{|c|}{$\mathrm{N}=\mathbf{2 0}(\%)$} \\
\hline Age (range) ${ }^{\bigotimes}$ & $66.5(52-82)$ \\
\hline \multicolumn{2}{|l|}{ Gender } \\
\hline Male & $4(20)$ \\
\hline Female & $16(80)$ \\
\hline \multicolumn{2}{|l|}{ ASA Grade ${ }^{\dagger}$} \\
\hline $1-2$ & $14(70)$ \\
\hline $3-4$ & $6(30)$ \\
\hline Duration post-laminectomy in months $s^{\otimes}$ & 39 \\
\hline \multicolumn{2}{|l|}{ Presenting symptoms } \\
\hline Backpain & $19(95)$ \\
\hline Radiation of pain & $10(50)$ \\
\hline Radicular neuropathy & $4(20)$ \\
\hline \multicolumn{2}{|l|}{ Levels involved } \\
\hline \multicolumn{2}{|l|}{ Anterolisthesis } \\
\hline $\mathrm{L} 2 / 3$ & $1(5)$ \\
\hline $\mathrm{L} 3 / 4$ & $8(40)$ \\
\hline $\mathrm{L} 4 / 5$ & $13(65)$ \\
\hline $\mathrm{L} 5 / \mathrm{S} 1$ & $2(10)$ \\
\hline \multicolumn{2}{|l|}{ Retrolisthesis } \\
\hline $\mathrm{L} 2 / 3$ & $4(20)$ \\
\hline $\mathrm{L} 3 / 4$ & $2(10)$ \\
\hline $\mathrm{L} 4 / 5$ & $1(5)$ \\
\hline $\mathrm{L} 5 / \mathrm{S} 1$ & $1(5)$ \\
\hline \multicolumn{2}{|l|}{ Extent of facetectomy } \\
\hline$<50 \%$ & $2(10)$ \\
\hline$>50 \%$ & $18(90)$ \\
\hline Baseline functional score & (SD) \\
\hline $\mathrm{ODI}^{\ominus}(\mathrm{SD})$ & $45.2(12.55)$ \\
\hline $\mathrm{ED}-5 \mathrm{D}^{\circ}(\mathrm{SD})$ & $0.66(0.13)$ \\
\hline
\end{tabular}

Anatomically, it is known that the surface area of the facet joints in the lumbar spine increases from L1 to S1 [11]. This could reflect the increase in shear forces transmitted across these joints in the lower segments. The facet joint angle in the transverse plane also changes from a mean of $25^{\circ}$ for L1-2 to $53^{\circ}$ for L5-S1 [12]. This obliquity enabled these joints greater efficiency in resisting shear loads.

In Abumi's evaluation of the stability of cadaveric lumbar spines after facet sparing and radical laminectomies in 1990, he concluded that the facet sparing laminectomy yielded a more stable spine [13]. Naturally, with surgery performed through a narrower corridor, concerns as to whether decompression can be adequately done surfaced. In response, Gill [14] described the use of semirigid probes to perform intraoperative assessment on the adequacy of neuroforaminal decompression. In his study, he reported no significant differences in interobserver or intraobserver measurements as determined by 3 independent observers.
A more recent study by Detwiler [15] provided direct comparison between both procedures, and demonstrated objective evidence showing facet sparing laminectomy producing less biomechanical instability and abnormal kinematic changes than the traditional Christmas Tree procedure. In addition, Christmas tree laminectomy also showed disproportionate increase in instability when the remaining stabilizing structures were resected. Despite the move towards facet sparing laminectomy, the incidence of post-facet sparing laminectomy spondylolisthesis remained variable from $8 \%$ to $31 \%[16,17]$.

Multiple other studies evaluated the biomechanics of the facet joints and their role in contributing to the overall stability of the lumbar spine. In the study by Lee [18], the effect of facetectomy on the motion segment was insignificant under flexion. However in extension, unilateral facetectomy and resection of the contralateral facet markedly altered the rotational motion and flexibility, as well as coupled motions. Unilateral complete facetectomy with resection of less than $100 \%$ of the contralateral facet generated a high facet load, reflecting the need to consider additional stabilization procedure in restoring the spinal strength and stability. Similar results by Teo in 2004 [19] showed that a unilateral and bilateral facetectomy of greater than $75 \%$ markedly altered the translational displacement and flexibility of the motion segment, also suggesting that fixation or fusion to restore strength and stability of the lumbar spine might be required for surgical intervention of greater than $75 \%$ facetectomy. Subsequently, it has been recommended that when performing a facet sparing laminectomy, one has to retain at least $50 \%$ of the facet bilaterally and sufficient pars to prevent instability. Otherwise, alternative forms of stabilizing spine should be considered. Partial facetectomy often involves removing more of the medially located inferior articular process of the superior vertebra than the laterally located superior articular process of the inferior vertebra. The key is to ensure that $50 \%$ of the joint has been preserved, thereby allowing at least some articulation and function of the facet joint. Although this form of assessment is arbitrary, it is comprehensive and reproducible.

Of the 20 patients who had transforminal lumbar interbody fusion performed in our institution following symptomatic post-laminectomy spondylolisthesis, fusion was achieved in all cases and functional scores improved significantly $(p<0.05)$ from baseline. Details of the operative parameters and 2 year functional scores are shown in Table 2. Implants used included pedicle screws e.g. Expedium (DePuy Spine, Raynham, MA), CD Horizon Legacy (Medtronic Sofamor Danek, Memphis, TN), Moss Miami (DePuy Spine, Raynham, MA), and Viper (DePuy Spine, Raynham, MA). Cages were also used e.g. Concorde (DePuy Spine, Raynham, MA), Capstone (Medtronic Sofamor Danek, Memphis, TN), Harm's (DePuy Spine, Raynham, MA), and Leopard (DePuy Spine, Raynham, MA). Bone substitutes used for packing of cages include local bone graft supplemented with dimineralised bone matrix. Two patients had inadvertent intra-operative dura tear that was primarily repaired without any further complications.

Apart from the stability contributed by the facet joints, there are also studies which show that the overall stability of 
the lumbar spine may also be dependent on the number of spinal levels that are decompressed. Monosegmental decompression of the lumbar spinal canal might not necessarily destabilize the motion segment but cause the distribution of the compensatory movement to be different at least in in vitro conditions [20].

Table 2. Operative Parameters and 2-Year Functional Scores

\begin{tabular}{|c|c|}
\hline Duration of Operation (mins) & Median (SD) \\
\hline 1 Level Fusion & $244.50(40.96)$ \\
\hline 2 Level Fusion & $285.50(56.95)$ \\
\hline 3 Level Fusion & $311.60(120.41)$ \\
\hline 4 Level Fusion & $329.00(86.27)$ \\
\hline
\end{tabular}

\begin{tabular}{|c|c|c|c|}
\hline Cages & $\underline{\mathbf{N}=\mathbf{2 0}}$ & Screw System & $\underline{\mathbf{N}=\mathbf{2 0}}$ \\
\hline Concorde & 9 & Expedium & 8 \\
\hline Capstone & 6 & CD Legacy & 7 \\
\hline Harm's & 3 & Moss Miami & 3 \\
\hline Leopard & 2 & Viper & 2 \\
\hline
\end{tabular}

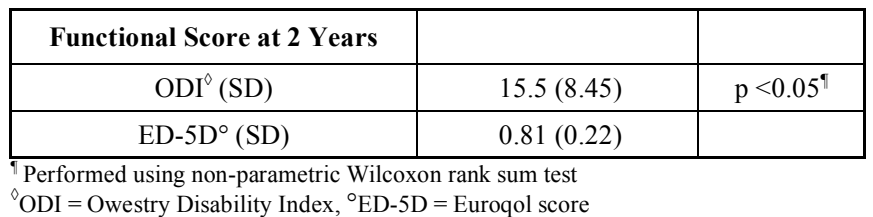

\section{THE ROLE OF LAMINOTOMY IN THE EARLY $21^{\text {ST }}$ CENTURY}

In the early $21^{\text {st }}$ century, the role of the posterior spinal complex as a stabilizer of the spine became increasingly recognized. In 2005, Vaccaro [21, 22] proposed the Thoraco-

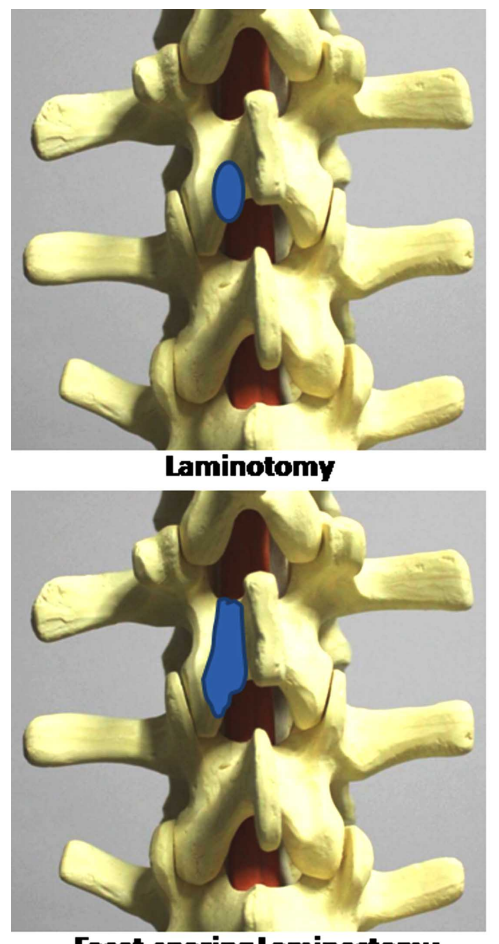

Facet-sparing Laminectomy lumbar Injury Severity Score (TLISS) for injuries to the thoracolumbar spine to determine spinal stability. In this score, additional emphasis is placed on the integrity of the posterior ligamentous complex. At the same time, another study by $\mathrm{Lu}$ et al. [23] showed that section of the anterior column and adjacent longitudinal ligaments resulted in a mean stiffness decrease by $22.8 \%$ of the intact value under anterior shear, and $23.9 \%$ under posterior shear. However, after removal of the posterior elements, a much larger change in shear stiffness was seen, and the mean sectioned stiffness dropped by $77.7 \%$ in anterior shear and $79 \%$ in posterior shear. Moreover, sectioning of the anterior column increased the anterior and posterior translation by 12 and $18 \%$ respectively. This was drastically lower than the anterior and posterior translation of 101.7 and $117.1 \%$ that occurred after the posterior elements were sectioned. As such, they concluded that the posterior elements including the musculoligamentous structures resist shear better than the anterior column but the anterior column allows for better axial load control so the 2 columns contribute different characteristics to the spine. Fig. (1) illustrates the different types of posterior decompression techniques different characteristics to the spine.

To date, there are different types of posterior decompression techniques (Fig. 1). Several studies have showed that laminotomy was both an effective and increasingly attractive option in the treatment of lumbar spinal stenosis $[17,24-30]$. This was substantiated by calf [31] and porcine [32] models showing laminectomy causing more destabilizetion of a spinal motion segment than laminotomy, Moreover, the presence of an intact posterior complex in laminotomy allows anchoring points for the supraspinous/interspinous ligaments; and together with the paraspinal musculature, provides a tension band effect that adds to the overall stability of the spine.
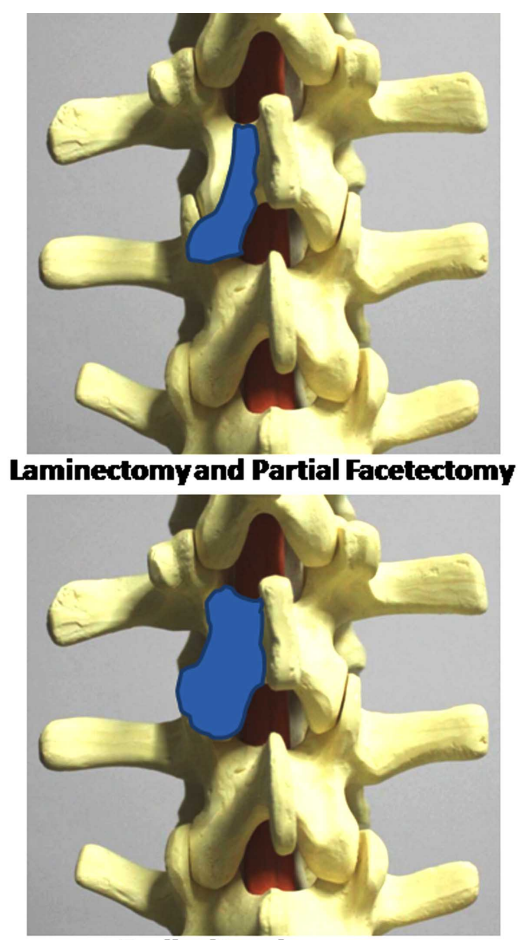

Radical Laminectomy

Fig. (1). Diagrammatic representation of different posterior decompression techniques. 
In the context of bilateral decompression, a recent cadaveric biomechanical study by Lee [33] showed that in lumbar flexion/extension, bilateral laminotomies resulted in an average increased flexion/extension motion of $14.3 \%$ between L2 to L5, whereas a full laminectomy resulted in an increase of $32.0 \%$. There was an approximate twofold increase in motion with laminectomy compared with bilateral laminotomies at every treated level. Stiffness was also decreased by an average of $11.8 \%$ after the 3-level laminotomies compared to $27.2 \%$ after the 3-level laminectomy. Despite these findings, many authors still recognize the presence of other factors which should be routinely considered when deciding the most suitable method of decompression. Patients with severe spinal stenosis may also benefit from laminectomy and fusion, since decompression alone using laminotomy may not be sufficient given the limited corridor for surgery.

\section{CONCLUSION}

The stability of the lumbar spine is contributed by various bony, discoligamentous, and muscular structures. Surgical decompression of spinal stenosis has to balance between adequate removal of bone and soft tissue for an effective decompression of neural structures, and sufficient retention of bone and soft tissue structures to maintain mechanical stability of the spine. This made laminotomy an attractive option if adequate decompression is deemed possible through a limited surgical corridor. Ultimately, the decision to perform laminectomy or laminotomy has to be a clinical judgment based on a combination of surgeon, patient and disease factors.

\section{CONFLICT OF INTEREST}

None declared.

\section{ACKNOWLEDGEMENT}

None declared.

\section{REFERENCES}

Lee HM, Kim HS, Kim DJ, Suk KS, Park JO, Kim NH. Reliability of magnetic resonance imaging in detecting posterior ligament complex injury inthoracolumbar spinal fractures. Spine (Phila $\mathrm{Pa}$ 1976) 2000; 25(16): 2079-84.

[2] Holdsworth F. Fractures, dislocations, and fracture-dislocations of the spine. J Bone Joint Surg Am 1970; 52(8): 1534-51. No abstract available.

[3] Mulholland RC. The myth of lumbar instability: the importance of abnormal loading as a cause of low back pain. Eur Spine J 2008; 17: 619-25.

[4] Fujiwara A, Tamai K, An HS, et al. Orientation and osteoarthritis of the lumbar facet joint. Clin Orthop Relat Res 2001; 385: 88-94.

[5] Fujiwara A, Tamai K, Yamato M, et al. The relationship between facet joint osteoarthritis and disc degeneration of the lumbar spine: an MRI study. Eur Spine J 1999; 8: 396-401.

[6] Vernon-Roberts B, Pirie CJ. Degenerative changes in the intervertebral discs of the lumbar spine and their sequelae. Rheumatol Rehabil 1977; 16:13-21.

[7] Videman T, Malmivaara A, Mooney V. The value of the axial view in assessing discograms. An experimental study with cadavers. Spine 1987; 12: 299-304.

[8] Natelson SE. The injudicious laminectomy. Spine 1986; 11: 966-9.
[9] Johnsson KE, Redlund-Johnell I, Ude'n A, et al. Preoperative and postoperative instability in lumbar spinal stenosis. Spine 1989; 14: 591-3.

[10] Lee CK. Lumbar spinal instability (olisthesis) after extensive posterior spinal decompression. Spine 1983; 8: 429-33.

[11] Panjabi MM, Oxland T, Takata K, Goel V, Duranceau J, Krag M. Articular facets of the human spine, Quantitative three-dimensional anatomy. Spine 1993; 18: 1298-310.

[12] Serhan HA, Varnavas G, Dooris AP, Patwadhan A, Tzermiadianos M. Biomechanics of the posterior lumbar articulating elements. Neurosurg Focus 2007; 22(1): E1.

[13] Abumi K, Panjabi MM, Kramer KM, et al. Biomechanical evaluation of lumbar spinal stability after graded facetectomies Spine 1990; 15: 1142-7.

[14] Gill TJ, Mason MD. Assessment of neuroforaminal decompression in degenerative spinal stenosis. Clin Orthop Relat Res 1998; (348): 135-9.

[15] Detwiler PW, Spetzler CB, Taylor SB, Crawford NR, Porter RW, Sonntag VK. Biomechanical comparison of facet-sparing laminectomy and Christmas tree laminectomy. J Neurosurg 2003; 99(Suppl 2): 214-20.

[16] Fox MW, Onofrio BM, Hanssen AD. Clinical outcomes and radiological instability following decompressive lumbar laminectomy for degenerative spinal stenosis: a comparison of patients undergoing concomitant arthrodesis versus decompression alone. J Neurosurg 1996; 85: 793-802.

[17] Fu YS, Zeng BF, Xu JG. Long-term outcomes of two different decompressive techniques for lumbar spinal stenosis. Spine (Phila Pa 1976) 2008; 33(5): 514-8.

[18] Lee KK, Teo EC, Qiu TX, Yang K. Effect of facetectomy on lumbar spinal stability under sagittal plane loadings. Spine (Phila Pa 1976) 2004; 29(15): 1624-31.

[19] Teo EC, Lee KK, Qiu TX, Ng HW, Yang K. The biomechanics of lumbar graded facetectomy under anterior-shear load. IEEE Trans Biomed Eng 2004; 51(3): 443-9.

[20] Delank KS, Gercek E, Kuhn S, et al. How does spinal canal decompression and dorsal stabilization affect segmental mobility? A biomechanical study. Arch Orthop Trauma Surg 2010; 130(2): 285-92.

[21] Vaccaro AR, Zeiller SC, Hulbert RJ, et al. The thoracolumbar injury severity score: a proposed treatment algorithm. J Spinal Disord Tech 2005; 18(3): 209-15.

[22] Vaccaro AR, Lehman RA Jr, Hurlbert RJ, et al. A new classification of thoracolumbar injuries: the importance of injury morphology, the integrity of the posterior ligamentous complex, and neurologic status. Spine (Phila Pa 1976) 2005; 30(20): 2325-33.

[23] Lu, WW, Luk, KD, Holmes AD, Cheung KM, Leong JC: Biomechanics of the posterior lumbar articulating elements shear properties of lumbar spinal joints and the effect of tissue sectioning on load sharing. Spine 2005; 30: E204-E209.

[24] Cavuçsoğlu H, Kaya RA, Türkmenoglu ON, et al. Midterm outcome after unilateral approach for bilateral decompression of lumbar spinal stenosis: 5-year prospective study. Eur Spine J 2007; 16: $2133-42$.

[25] Koch-Wiewrodt D, Wagner W, Perneczky A. Unilateral multilevel interlaminar fenestration instead of laminectomy or hemilaminectomy: an alternative surgical approach to intraspinal space-occupying lesions: technical note. J Neurosurg Spine 2007; 6: 485-92.

[26] Postacchini F, Cinotti G, Perugia D, et al. The surgical treatment of central lumbar stenosis. Multiple laminotomy compared with total laminectomy. J Bone Joint Surg Br 1993; 75: 386-92.

[27] Sasaki M, Abekura M, Morris S, et al. Microscopic bilateral decompression through unilateral laminotomy for lumbar canal stenosis in patients undergoing hemodialysis. J Neurosurg Spine 2006; 5: 494-9.

[28] Thomas NW, Rea GL, Pikul BK, et al. Quantitative outcome and radiographic comparisons between laminectomy and laminotomy in the treatment of acquired lumbar stenosis. Neurosurgery 1997; 41: 67-74.

[29] Thomé C, Zevgaridis vD, Leheta O, et al. Outcome after lessinvasive decompression of lumbar spinal stenosis: a randomized comparison of unilateral laminotomy, bilateral laminotomy, and laminectomy. J Neurosurg Spine 2005; 3: 129-41.

[30] Tsai RY, Yang R, Bray RS Jr. Microscopic laminotomies for degenerative lumbar spinal stenosis. J Spinal Disord 1998; 11: 38994. 
[31] Rao RD, Wang M, Singhal P, et al. Intradiscal pressure and kinematic behavior of lumbar spine after bilateral laminotomy and laminectomy. Spine J 2002; 2: 320-6.

[32] Tai CL, Hsieh PH, Chen WP, et al. Biomechanical comparison of lumbar spine instability between laminectomy and bilateral lamino- tomy for spinal stenosis syndrome-an experimental study in porcine model. BMC Musculoskelet Disord 2008; 9: 84.

[33] Lee MJ, Bransford RJ, Bellabarba C, et al. The effect of bilateral laminotomy versus laminectomy on the motion and stiffness of the humanlumbar spine: a biomechanical comparison. Spine (Phila Pa 1976) 2010; 35(19): 1789-93.

Received: March 08, 2012

Revised: April 01, 2012

Accepted: April 03, 2012

(C) Hey et al.; Licensee Bentham Open.

This is an open access article licensed under the terms of the Creative Commons Attribution Non-Commercial License (http://creativecommons.org/licenses/by$\mathrm{nc} / 3.0 /$ ), which permits unrestricted, non-commercial use, distribution and reproduction in any medium, provided the work is properly cited. 